\title{
基于工程实践的 C 实验教学改革
}

\section{Reform of C Experimental Teaching Based on Engineering Practice 帅剑平 袁暗}

\author{
Jianping Shuai Yu Yuan
}

桂林电子科技大学

中国·广西 桂林 541004

Guilin University of Electronic Technology,

Guilin, Guangxi, 541004, China
【摘要】在众多理工科院校中,都把 $\mathrm{C}$ 语言作为编程的入门级语言, $\mathrm{C}$ 语言本身具有很 强的实践性, 相应的实验教学显得尤为重要。论文通过分析教学中存在的问题, 利用工程 实训的教学方式进行实践探索, 以此提高 $\mathrm{C}$ 语言的综合能力。

【Abstract】In many science and engineering colleges and universities, the $\mathrm{C}$ language is regarded as the entry-level language of programming, and the $\mathrm{C}$ language itself is very practical. The corresponding experimental teaching is particularly important. Through analyzing the existing problems in teaching, this paper makes use of the teaching methods of engineering training to explore the practice, so as to improve the comprehensive ability of C language.

【关键词】工程实训; 实践性; 综合能力

【Keywords \engineering training; practicality; integrated capacity

【DOI】10.36012/sde.v2i1.782

\section{1 引言}

信息技术的发展日新月异,新技术、新事物正以前所未有 的速度改变着人类的生活方式, 加快了社会生产力的发展, 也 提高了人们的生活质量 ${ }^{[1]}$ 。与此同时, 社会生活、工作、学习等 各层面对计算机使用的高度依赖，也给计算机教育提出了一 个全新的挑战。随着计算机的高度普及, $\mathrm{C}$ 语言的教学也应顺 应时代的发展而改变, $\mathrm{C}$ 语言程序设计是理工类院校必修的 计算机基础课程, 作为高校学生的必修课, 在学习过程中, 不 仅要让学生掌握 $\mathrm{C}$ 语言的理论知识, 还应让学生具备实际动 手编程的能力, 最终使学生能够灵活运用其解决学习和生活 中的实际问题。

\section{2 课程存在的问题}

(1)盲目追求自主权。某些高校自主对 $\mathrm{C}$ 语言实行教学改 革, 自行组织教学内容和考试, 这样做带来了机遇也迎来了挑 战。部分高校在追求自主权的同时,完全抛弃以往构建的课程 体系, 缩减授课学时, 自行随意编制教材、计划、大纲 ${ }^{[2]}$, 在不经 过研讨和试点直接开展全面教学, 难以保障教学质量和水平。

(2)学生水平参差不齐。受经济、个人兴趣等因素的制约和 影响, 学生入学的计算机水平存在较大差异, 有些学生入学时 对计算机已十分通晓和熟练, 也有极少部分中、西部不发达地
区的学生从未接触过计算机。在部分学生计算机基础操作能 力都欠缺的情况下进行 $\mathrm{C}$ 语言的教学更加难上加难。

(3)教学形式单一。在理论教学方面, 教师根深蒂固的传统 教学观念无法激起学生的课堂兴趣, 教授过程侧重枯燥的概 念教学, 致使学生学习效率和兴趣低下, 教学质量难以保障; 实验教学方面, 按部就班的讲解、陈旧的教学设计、简单的教 学内容使得讲解过程生硬、复杂内容讲解不透, 没有结合实际 学习和生活中的实际问题来设计合理的教学内容, 没有更好 地把各知识点融入到教学案例中。

(4)教学与专业脱节。众多基础课程的授课过程基本上都 按统一的大纲进行教学, 与专业脱节, 在 $\mathrm{C}$ 语言的教学中也 是如此, 没有考虑从专业知识来设计教学内容。

(5)不立足本校生源特点开展教学。自大学扩招以来, 不同 时期、不同学校、同一学校不同时期的生源都发生了很大的改 变, 在教学中没有考虑时代发展和学生能动性以及本校特色 开展教学工作。

\section{C 语言实验改革问题的思考}

高校人才培养 $\mathrm{C}$ 语言编程能力所出现的上述问题, 需要 认真研究以往教学的经验和不足, 从中发现问题进而解决问 题 ${ }^{[3]}$ 。结合近来年 C语言实验教学中存在的问题, 提出以下几 点建议: 
(1)立足本校教学理念开展教学。C 语言实验教学应以在 本校教学体系的基础上进行改革和创新, 盲目追求创新、大幅 度更改教学大纲、脱离本源基础知识等, 反而容易导致教学上 的偏差。应立足在原有教学的基础上, 以试点班级的方式进行 试探性、渐进性的改革, 有成效再扩大改革的范围。

(2)教学内容推陈出新。C 语言课程是一门实践性非常强 的课程, 与理论相配套的实验课程体系旨在帮助学生巩固、串 联理论知识, 以此来提高实践能力。教学内容的设计应减少独 立知识点的验证性实验, 此类内容难以使知识点融会贯通, 学 生兴趣偏低, 导致学生解决实际问题的能力产生缺欠。

(3)工程实践为导向。工程教育专业认证要求培养学生不 仅具有扎实的专业素质, 更重要的是有提出问题、解决问题的 能力 ${ }^{[4]}$ 。以工程实践为导向, 利用渐近式任务驱动实践课题将 知识点贯通, 循序渐进地引导学生从独立的知识点的学习到 最终课题的完成, 以剥洋葱式的方式对大的问题逐层分解, 使 学生具备应用这些思维方法分析和解决实际问题的能力。

(4)更新教学方法。在授课过程中不要填鸭式把所有内容 灌输给学生, 要给学生留有一定的思考空间, 让部分内容通过 学生的主动思考体会出来, 这样既可以锻炼学生主动思考问 题、解决问题的能力, 同时学生在学习过程中还可以获得一定 的成就感。此外,著名教育学家斯维特洛夫曾经说过，“教育家 需要做的最主要的, 就是将第一位的助手收纳起来, 它就是幽 默。”教师在授课过程中应富有幽默性, 让学生能够轻松学 习, 教师富幽默性的语言能够很好地吸引学生的注意力, 并且 使自己与学生都感到轻松。

(5)教学与专业相结合。教师应结合所教学生的专业进行 教学, 制订与学生专业相符的教学内容, 不同专业应有不同的 侧重点。例如, 对于电子类专业的教学内容的设计在初期的学 习可对求导、微积分用程序的方式表达, 引导学生从数学思维 到计算机思维进行转变 ${ }^{[5]}$ 。

6)丰富课程资源。教师提供给学生的教学资源往往是自 己的讲课课件、习题答案等, 内容、形式都过于单一。随着网络 技术的发展，校园网的迅速兴起为教师创建多样化的教学资 源提供了平台, 部分高校更是提供了智慧校园的信息平台, 教 师可以充分利用这些信息平台创建本课程的课程网站, 将本
课程的相关教学资源 (课件、习题、讨论专题和教学视频等)放 在网站上供学生自主学习以供学生查漏补缺, 亦可增加师生 间的互动性和学生问题反馈的及时性。

(7)课程考核改革。学生的学习依靠考核来对教学质量进 行评估, 因此考核改革需要遵守合理性、科学性的原则。一方 面, 能够对学生的学习效率与教师的教学质量进行监督与评价; 另一方面, 能够运用合理的考核方式对学生学习进行合理引 导。改变单一的期末考试定终身的考核方式, 重视过程和工程 实践能力的考核, 从多方面对学生进行考核 ${ }^{[6}$ 。课程总成绩的构 成由平时成绩、阶段考核、期末考核按 30\%、30\%、40\%的比例 进行划分; 平时成绩的构成又包括考勤、作业、随堂奖励性考 核等。

\section{4 结语}

C 语言实验教学起到承前启后的作用, 在学习中培养学 生的逻辑思维能力、分析和解决问题的能力。在教学中会存在 各类的问题, 这些都需要教师根据实际情况解决, 教师首先要 具有创新思维、改革精神 ${ }^{[7]}$, 才能够在教学中不断改进和创新, 才能激发学生的学习意识和学习热情。因此,高校必须跟上时 代发展的脚步, 不断创新教学观念, 从而培养和提高学生的工 程实践能力, 为学生的后继课程和将来的健康发展奠定良好 的基础。

\section{参考文献}

[1]杨洁. 试析高等职业教育课程体系改革 [J].时代教育(教育教学 版),2009(4):27

[2]王蓉. 高校计算机教育的探讨[J].成都电子机械高等专科学校 学报,2003(1):42-44.

[3]李廉. 以计算思维培养为导向 深化大学计算机课程改革 [J].中 国大学教学,2013(4):7-11.

[4]陈振庆.新升本科院校计算机专业教育存在问题及对策 $[\mathrm{J}]$.中 国西部科技,2009(7):81-85.

[5]陈国良,董荣胜.计算思维与大学计算机基础教育 [J].中国大学 教学,2011(1):7-11.

[6]谭浩强.C 程序设计(第四版)[M]. 北京:清华大学出版社,2010.

[7] 马红.C 语言程序设计教学改革与实践 [J].山东行政学院山东 省经济管理干部学院学报,2006(S1):79-80. 